\title{
Study of dietary intake of micro and macronutrients and comparison with the Recommended Daily Allowance (RDA)
}

\author{
Navneet Agrawal ${ }^{1}$, Ambrish Singh ${ }^{2}$, Seema Rana $^{3 *}$ \\ ${ }^{1}$ Consultant Diabetologist, ${ }^{2}$ Independent statistician, ${ }^{3}$ Consultant Nutritionist, Diabetes, Obesity \& Thyroid Centre, Gwalior, Madhya \\ Pradesh, India
}

*Corresponding Author: Seema Rana

Email: seemar02@gmail.com

\begin{abstract}
Introduction: For the prevention of symptoms of deficiency and to maintain satisfactory level of the nutrient in the body, consumption of nutrients as par Recommended Daily Allowance (RDA) is very important.

Aims and Objectives: To evaluate the level of micro and macro nutrients consumption among the study participants and their comparison with the current RDA recommendation.

Materials and Methods: Five hundred and two patients and their attendants visiting the OPD of Diabetes, Obesity \& Thyroid Center, Gwalior, Madhya Pradesh for their routine follow ups were studied. Sociodemographic details including age, sex, height and weight were recorded. Dietary recall of two days was taken on a predesigned proforma. Details of the intake of various macronutrients and micronutrients were estimated by Dietcal software.

Results: Mean age of study participants was $44.51 \pm 12.53$ years with male preponderance $(51.8 \%)$. Females were found to consume less macronutrients $(\mathrm{p}<0.001)$ compared to males. In overall population, consumption of vitamin B12, iron, zinc and magnesium was $98.75 \%$, $37.415,45.5 \%$ and $8.07 \%$ lower than the RDA whereas participants were consuming $155.27 \%$ more selenium than the RDA. Carbohydrate consumption was also $50.04 \%$ more than the RDA whereas consumption of protein was $37.53 \%$ lesser than the RDA. In present study participants were taking too much fat which was more than $115 \%$ than the RDA.

Conclusion: Present study population had lower amount of protein, higher amount of fats and carbohydrates intake; micronutrients intake was also very low as compared to RDA.
\end{abstract}

Keywords: Recommended daily allowance, Nutritional deficiency, India, macronutrients, Micronutrients.

\section{Introduction}

Indian Council of Medical Research is responsible for revising requirements of nutrients and recommended dietary allowances (RDAs) periodically. This provide guidance to population and help in making policy related to nutrients requirements conforming a healthy population. ${ }^{1}$

There is a difference between the nutrient requirement of any individual and dietary allowances of the population. Requirements of nutrients depends on individual's age, sex, weight of the body and physiological and metabolic status however, dietary allowances contemplate individual variation within the group, effect of processing and bioavailability of the nutrient from the diet and diet quality. 2

In Indian population, micronutrient malnutrition is a common and serious problem. Reports of National Nutrition Monitoring Bureau is alarming as intake of micronutrient of $70 \%$ of the Indian population is less than $50 \%$ of the RDA. ${ }^{3}$ Micronutrient malnutrition can lead to high morbidity and mortality. 4

There is an immediate need to control micronutrient malnutrition on a priority basis. However, balanced consumption of macronutrients (carbohydrates, protein and fats) is also important for the prevention of chronic diseases such as diabetes and cardio vascular diseases. Hence in present study we tried to evaluate the dietary intake of both micro and macronutrients and comparing their level with the current available RDA.

\section{Materials and Methods}

Present prospective study was performed on 502 patients coming to OPD of Diabetes, Obesity \& Thyroid Center, Gwalior, Madhya Pradesh for their routine follow ups.

After recording sociodemographic details including age, sex, height and weight, details of two days dietary recall was obtained from each participant and recorded in a predesigned proforma. Details of dietary recall were entered in the Dietcal software to obtain the daily consumption of various macronutrients and micronutrients. Daily intake of various macro and micronutrients were compared with Recommended Dietary Allowance (RDA) proposed by the ICMR Expert Committee.

All the data analysis was performed using IBM SPSS ver. 20 software. Descriptive analysis was performed to obtain the baseline characteristics of the participants. Frequency distribution and Cross tabulation was performed to prepare the tables. Quantitative data is expressed as mean and standard deviation whereas categorical data is expressed as percentage. Means were compared using independent sample $t$ test and $\mathrm{p}$ value of $<0.05$ was kept as significant.

\section{Results}

Majority of the participants were male $(51.8 \%)$ and had age between $31-40$ years $(26.5 \%)$ followed by $41-50$ years $(25.5 \%)$ and $51-60$ years $(23.5 \%)$. Mean age of study cohort was $44.51 \pm 12.53$ years. Out of 502 participants, 115 $(22.9 \%)$ were overweight and $308(61.4 \%)$ were obese. Mean BMI was $26.90 \pm 4.93 \mathrm{~kg} / \mathrm{m} 2$. 
Table 1: Mean Nutrition intake by the study participants

\begin{tabular}{|c|c|c|c|c|c|}
\hline Nutrients & N & Minimum & Maximum & Mean & Std. Deviation \\
\hline Protein & 502 & 15.37 & 87.79 & 37.48 & 11.52 \\
\hline Total Fat & 502 & 13.72 & 149.52 & 53.60 & 19.77 \\
\hline Carbohydrate & 502 & 90.00 & 369.42 & 195.05 & 56.89 \\
\hline Calcium & 502 & 84.97 & 1061.34 & 420.56 & 171.96 \\
\hline Copper & 502 & .48 & 2.51 & 1.27 & 0.34 \\
\hline Iron & 502 & 2.96 & 21.18 & 10.64 & 2.86 \\
\hline Magnesium & 502 & 111.96 & 641.47 & 312.53 & 89.27 \\
\hline Selenium & 502 & 5.19 & 226.16 & 91.90 & 33.61 \\
\hline Zinc & 502 & 2.16 & 13.81 & 6.54 & 1.87 \\
\hline Vitamin B12 & 101 & .00 & .47 & 0.03 & 0.06 \\
\hline
\end{tabular}

On performing ANOVA between age group and nutrition it was revealed that calcium level was significantly lower among the old age groups (61-70 years) and those having 31-40 years of age $(\mathrm{p}<0.001)$. However, we did not find any association of age with any of the nutrients level. No significant association was found between BMI groups and nutrients received by the subjects ( $p>0.05)$.

Table 2: Comparing nutrition among the genders

\begin{tabular}{|c|c|c|c|}
\hline Nutrients & Female & Male & P value \\
\hline Protein & $33.14 \pm 9.89$ & $39.45 \pm 11.77$ & $<0.001$ \\
\hline Total fat & $48.14 \pm 16,74$ & $54.77 \pm 21.57$ & 0.002 \\
\hline Carbohydrate & $174.1 \pm 51.12$ & $206.94 \pm 58.92$ & $<0.001$ \\
\hline Calcium & $394.45 \pm 155.23$ & $428.21 \pm 183.18$ & 0.075 \\
\hline Copper & $1.13 \pm 0.29$ & $1.35 \pm 0.37$ & $<0.001$ \\
\hline Iron & $9.37 \pm 2.44$ & $11.22 \pm 3.00$ & $<0.001$ \\
\hline Magnesium & $274.38 \pm 71.45$ & $331.60 \pm 96.65$ & $<0.001$ \\
\hline Selenium & $77.64 \pm 27.15$ & $99.87 \pm 35.28$ & $<0.001$ \\
\hline Zinc & $5.73 \pm 1.53$ & $6.99 \pm 2.01$ & $<0.001$ \\
\hline Vitamin B12 & $0.043 \pm 0.09$ & $0.36 \pm 0.07$ & 0.723 \\
\hline
\end{tabular}

Table 3: Comparing daily intake of nutrients with the RDA among subjects

\begin{tabular}{|c|c|c|c|}
\hline Nutrients & RDA & Mean & Percentage \\
\hline Protein & 60 & $37.48 \pm 11.52$ & -37.53 \\
\hline Total Fat & 25 & $53.60 \pm 19.77$ & +114.4 \\
\hline Carbohydrate & $130 \mathrm{~g} /$ day & $195.05 \pm 56.89$ & +50.04 \\
\hline Calcium & $800-1000$ & $420.56 \pm 171.96$ & -53.27 \\
\hline Copper & 1.7 & $1.27 \pm 0.34$ & -25.27 \\
\hline Iron & 17 & $10.64 \pm 2.86$ & -37.41 \\
\hline Magnesium & 340 & $312.53 \pm 89.27$ & -8.07 \\
\hline Selenium & 36 & $91.90 \pm 33.61$ & +155.27 \\
\hline Zinc & 12 & $6.54 \pm 1.87$ & -45.5 \\
\hline Vitamin B12 & 2.4 & $0.03 \pm 0.06$ & -98.75 \\
\hline
\end{tabular}

\section{Discussion}

Consumption of sufficient nutrition as recommended by the RDA is an important issue in order to improve the health status and to prevent the non-communicable diseases in developing countries. ${ }^{5}$

In present study, females were found to consume less nutrients as compared to males in their $\operatorname{diet}(\mathrm{p}<0.001)$ which means females are malnourished as compared to males in the present study.

In present series iron intake was 37.415 lower than the RDA. In line with present series, a study from Iran by Azadbakhtet al including 289 healthy female reveled that
Iron intake was $76 \%$ lower as compared to RDA. ${ }^{6}$ In present study, intake of calcium was $53.27 \%$ lesser than the RDA. A study from Iran however, reported very high deficiency of calcium where women were taking only $10 \%$ of the RDA. ${ }^{6}$ In present study participants were consuming $155.27 \%$ more Selenium than the RDA. In line with present study Daily selenium intakes of Isfahanian female youths was also $126 \%$ more than the RDA. ${ }^{6}$ Consumption of Vitamin B12 was very low in present study which was $98.75 \%$ lower than the RDA that means in our study only $1.25 \%$ of Vitamin B12 was being consumed as per the RDA which is very alarming. A study from Delhi is in line with the present 
study finding where lower consumption of vitamin B12 was reported among the vegetarians as compared to nonvegetarians which was below the RDA level. ${ }^{7}$ However, in present study we did not checked the micronutrient level between the vegetarians and non-vegetarians. Vegetarians often develop vitamin B12 deficiencies compared to nonvegetarians due to the reduced bio-availability from plant sources. ${ }^{8,9}$ In our series participants were also deficient in zinc also, as they were consuming $45.5 \%$ lesser zinc against the RDA. Shridhar et al also reported lower consumption of zinc in vegetarians. ${ }^{7}$ Magnesium was the only micronutrients which was being consumed near to RDA. However, it was also $8.07 \%$ lesser than the RDA. Ina similar series by Gupta et al reported that majority of the adolescent girl's micronutrients (calcium, iron, zinc, folate, vitamin B6, niacin, riboflavin, and vitamin C) was found less than the RDA value. ${ }^{10}$

A study from New Delhi by Shridhar et al performed multivariate analysis for macro-nutrients and found that vegetarians were consuming less total fat $(p=0.002)$ and protein $(\mathrm{p}<0.0001)$ and more carbohydrate $(\mathrm{p}<0.0001)^{7}$ which is in line with the present study findings where carbohydrate consumption was also $50.04 \%$ more than the RDA whereas consumption of protein was $37.53 \%$ lesser than the RDA. In present study participants were taking too much fat which was more than $115 \%$ than the RDA.A study from Karnataka involving 422 adolescent girls reported that among macronutrient, percentage of adequacy of protein (101.9\%) was found slightly higher than the RDA. The fat intake (47.89 g/day) was found apparently higher than RDA among adolescent girls. ${ }^{10}$

It is very evident that consumption of micro and macro nutrients both as per the recommended RDA is very much required for proper growth and to maintain the health of individual. Inadequacy of these can results in to imbalance in metabolic function and can lead to several morbidity and mortality. Hence it is very important to adopt nutrition education model to educate the people on the balanced nutrition. Previous studies have revealed the usefulness of nutrition education on improving dietary intake and proving a healthy eating pattern. ${ }^{11}$

Present study had few limitations; small sample size was the main. Secondly we have not compared the micro and macro nutrients levels between the vegetarian and nonvegetarian people and based on their sociodemographic parameters. There is a need of large randomized clinical trial to provide strength to present study findings.

\section{Conclusion}

Present study has revealed that among micronutrients consumption of calcium, copper, iron, magnesium, zinc and vitamin B12 was below the RDA however selenium was being taken in very high among from diet.Among macronutrients carbohydrate and fat consumption was very high whereas protein consumption was below the RDA. This mean population had lower amount of nutrients intake compared to the guidelines. So, it seems that nutrition education programs are needed in this area to promote the consumption of healthy food items containing these micro and macro nutrients.

\section{Source of funding}

None.

\section{Conflict of interest}

None.

\section{References}

1. Nutrient requirements and recommended dietary allowances for Indians. A report of the expert group of the Indian Council of Medical Research. Hyderabad: National Institute of Nutrition; 2010. Indian Council of Medical Research.

2. Nair KPM, Augustine LF. Country-specific nutrient requirements $\&$ recommended dietary allowances for Indians: Current status \& future directions. Indian J Med Res 2018;148(5):522-530.

3. National Nutrition Monitoring Beurau. Hyderabad: National Institute of Nutrition; 2002.

4. Kotecha PV. Micronutrient Malnutrition in India: Let Us Say "No" to it Now. Indian J Community Med 2008;33(1):9-10.

5. Azadbakht L, Mirmiran P, Esmaillzadeh A, Azizi F. Dairy consumption is inversely associated with the prevalence of the metabolic syndrome in Tehranian adults. Am J Clin Nutr 2005;82:523-30.

6. Azadbakht L, Esmaillzadeh A. Macro and Micro-Nutrients Intake, Food Groups Consumption and Dietary Habits among Female Students in Isfahan University of Medical Sciences. Iran Red Crescent Med J 2012;14(4):204-209.

7. Shridhar K, Dhillon PK, Bowen L, Kinra S, Bharathi AV, Prabhakaran $\mathrm{D}$ et al. Nutritional profile of Indian vegetarian diets - the Indian Migration Study (IMS). Nutr J 2014;13:55.

8. Indian Council of Medical Research: Nutrient Requirements and Recommended Dietary Allowances for Indians, A report of the expert group of the Indian Council of Medical Research; 2010

9. Antony AC: Vegetarianism and vitamin B-12 (cobalamin) deficiency. Am J Clin Nutr 2003;78(1):3-6.

10. Gupta A, Noronhab JA, Shobhab, Gargc M. Dietary intake of macronutrients and micronutrients among adolescent girls: A cross sectional study. Clin Epidemiol Global Health 2018;6(4):192-7.

11. Sharifirad GH, Najimi A, Hassanzadeh A, Azadbakht A. Application of BASNEF educational model for nutritional education among elderly patients with type 2 diabetes: Improving the glycemic control. J Res Med Sci 2011;16:114958.

How to cite: Agrawal N, Singh A, Rana S. Study of dietary intake of micro and macronutrients and comparison with the Recommended Daily Allowance (RDA). IP J Nutr Metab Health Sci 2020;3(1): 